\title{
FUNCTIONAL DESIGN AND EXPERIMENTAL ANALYSIS OF A NEW PINION-ENGAGING MECHANISM FOR STARTER MOTORS
}

\author{
Lajos NAGY \\ Robert Bosch Department of \\ Mechatronics \\ University of Miskolc \\ Miskolc, Hungary \\ nagy.lajos@uni-miskolc.hu
}

\author{
Tamás SZABÓ \\ Robert Bosch Department of \\ Mechatronics \\ University of Miskolc \\ Miskolc, Hungary \\ tamas.szabo@uni-miskolc.hu
}

\author{
Endre JAKAB \\ Robert Bosch Department of \\ Mechatronics \\ University of Miskolc \\ Miskolc, Hungary \\ jakab.endre@uni-miskolc.hu
}

\begin{abstract}
This paper discusses a part of an industrial project which can be solved by mechatronic design method. In general, it follows VDI Guidelines 2206 and applying a model-based design tool, focusing conceptual design stage. The objective of the project was to design and construct a new pinion engaging mechanism for starter motor.
\end{abstract}

Keywords-mechatronic system, mechatronic design, cam mechanism, starter motor

\section{INTRODUCTION}

Many theories and methods were and have been developed during the last fifty years such as systematic design methodology [2], decision-based design theory, Theory of Inventive Problem-Solving (TRIZ), computational design theory, Axiomatic Design [12], General Design Theory, Formal Design Theory and Axiomatic Theory of Design Modeling, etc. [12]. Several papers [14], [15], [21] discusses the difference between of these theories Nowadays, these theories are taught in many engineering schools and reported being applied industrially.

The objective of this paper is to present the solution of a particular industrial task by VDI Guidelines 2206. The project was born in 2006 from an industrial commission, with the objective of developing and constructing a new, state-of-theart pinion engaging mechanism (PEM) for starter motors for passenger cars. The contents of the paper are related to this objective.

\section{PINION ENGAGING MECHANISM}

The PEM is a part of a components of the starter motor. The purpose of the PEM is to be able to switch a high current (about 600-1200 Amperes) by means of relatively low control current [5]. It performs the following two functions: it moves the drive pinion outwards so that engages in the engine's ring gear and it closes the switch which completes the starter motor's primary electric circuit. The two part functions are in close connection with each other. There are two basic types of starter motor pinion-engaging mechanisms: the direct operation switch, where the starter motor and the pinionengaging mechanism are uni-axial, and the indirect operation switch, where the central line of the switch and the axis of the starter motor do not coincide and the forward movement of the pinion gear is supported by a lever or a release gear.

The functional drawing of the analyzed PEM is shown in Figure 1., where Item 1 is the solenoid switch (electromagnet), item 2 is a pinion engaging lever (translational to translational transducer), item 3 is the drive pinion. The drive pinion can do translational and also rotational movement.

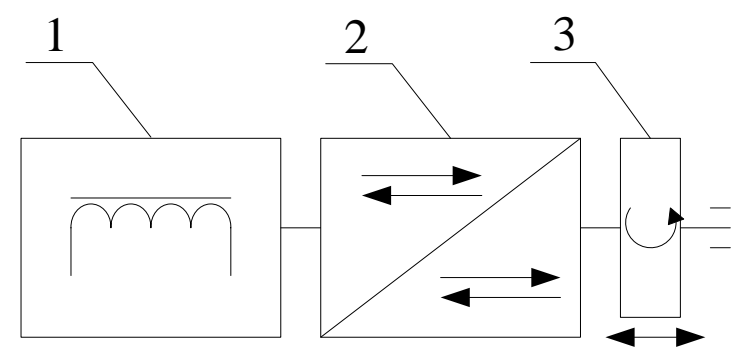

Fig. 1.:Functional drawing of the PEM

\section{MECHATRONIC DESIGN}

Mechatronic system design is modern interdisciplinary design procedure. Mechatronic systems emerge from a suitable combination of mechanics, electronics and information processing. The very popular German VDI guidelines 2206 describe an integrated model of product development (see in Figure 2.). There are based on the traditional design methods [15-17] and respective design theories developed mainly by PAHL, BEITZ, HUBKA, KOLLER, FRANKE, and ROTH. The V- model envisages a macrocycle, which based on the requirements of the product development provides for the system design which is subsequently transferred to the now parallelised domain design [8]. The guidelines mainly aim at supplying generally accepted methodical and branch independent bases for developing and designing technical systems and products for a wide range of applications [3]. They provide a systematic and 
planned procedure for solving technical problems. The VDI product development model is based on a system-oriented flexible procedural model. Based on the $\mathrm{V}$ model the requirements can be divided into four large groups on the basis of [13]: Functional or basic requirements (determining the actual objective of the task, always assigned to the particular task). General requirements (general main requirements set for starters). Priority requirements, typical of the age (requirements with the greatest impact on development strategies). Requirements typical of all machines (Table 1.). In [6], [7] the electromechanical model of the PEM is described. The results are used in the functional and general requirements.

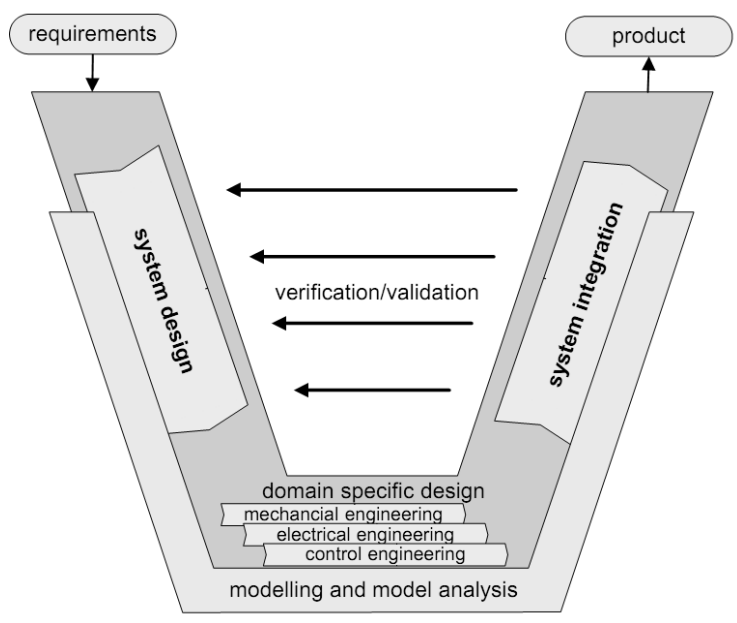

Fig 2.: VDI 2206 V model [17]

TABLE I. Requirements list

\begin{tabular}{|c|c|}
\hline \multicolumn{2}{|l|}{ List of requirements } \\
\hline \multirow[t]{2}{*}{$\begin{array}{l}\text { Functional } \\
\text { requirements }\end{array}$} & $\begin{array}{l}\text { Engaged and disengaged the drive pinion- } \\
\text { flywheel connection, positioning, axial } \\
\text { movements }(13,5 \mathrm{~mm})\end{array}$ \\
\hline & new technical solution \\
\hline \multirow{3}{*}{ General requirements } & $\begin{array}{l}\text { a great number of connections }(>250.000) \text {, } \\
\text { short connection time }(<30 \mathrm{~ms})\end{array}$ \\
\hline & building block principle, modular design \\
\hline & low level of noise \\
\hline \multirow{4}{*}{ Priority requirements } & $\begin{array}{l}\text { rapid repair, service or replacement in case } \\
\text { of faults }\end{array}$ \\
\hline & easy fit in many different engines \\
\hline & $\begin{array}{l}\text { operability also in extreme weather } \\
\text { conditions }\end{array}$ \\
\hline & reliability \\
\hline \multirow{5}{*}{$\begin{array}{l}\text { Requirements typical of } \\
\text { all machines }\end{array}$} & compactness and small weight \\
\hline & long life \\
\hline & manufacturing requirements \\
\hline & industrial law requirements \\
\hline & other (e.g. servicing) requirements \\
\hline
\end{tabular}

Traditional methods [17-19], for Mechatronics design are often based on a sequential approach, where the mechanical structure is designed first. Mechanical systems generate certain motions or transfer forces or torques. For an oriented command of, e.g., displacements, velocities or forces [3]. The task is how to develop a new PEM construction. First of all it should be analyze the different motion transducers. Figure 3 . shows a design procedure which is applying machine tool design [8].

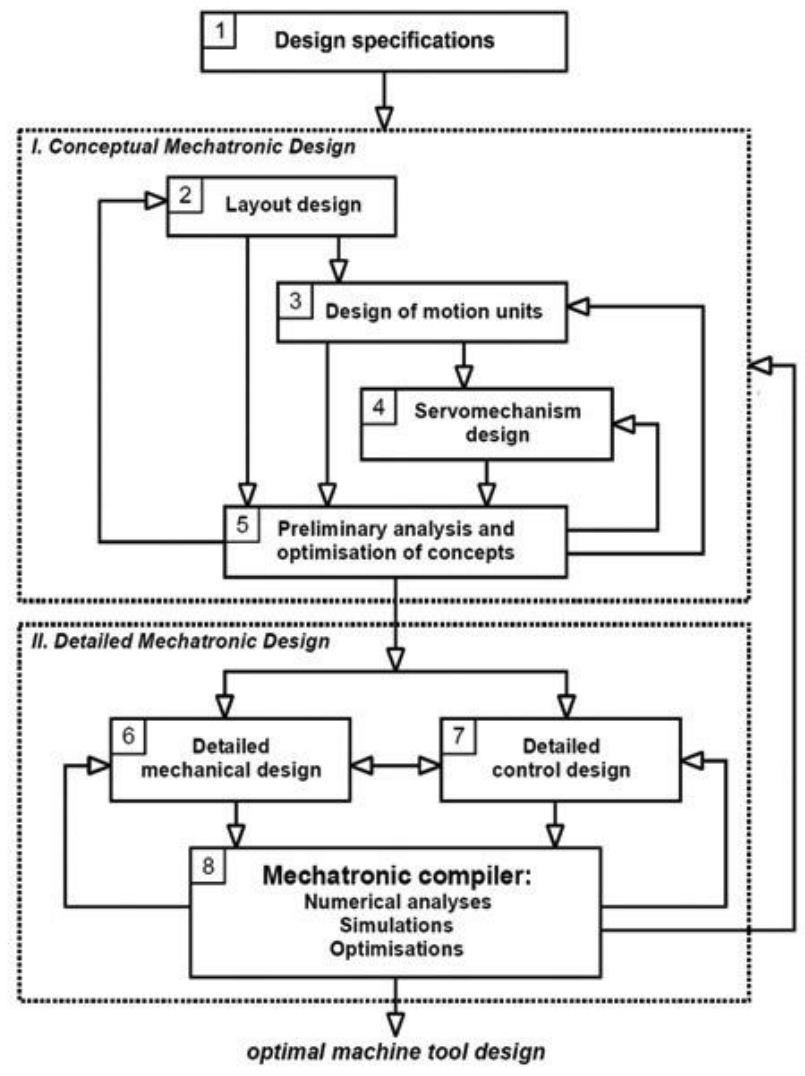

Fig 3.:Model-based design tool [6]

Recognizing that the two most common types of available power inputs are: (1) rotational (electric motor, ${ }^{-}$fluid motor, crank, etc.), and (2) translational (hydraulic or pneumatic cylinder, motor and ball screw, etc.), The first step in the conceptual mechatronic design is: the types of motion that are transmitted between the input and output members, i.e. translation-to-translation or translation-to-rotation, without any regard to specific axes, and the type of patial relationship between the input and the output axes, i.e. parallel, perpendicular, or skew [1].

The aim of the new mechanism, is built in coaxial with the electric motor shaft. The point of this construction is the following: the pinion's axial movement ensured with a DC servo motor combined with cam mechanism. The DC servo motor is energized only to perform pinion-engagement and not during the whole starting process. The control of the PEM can be done independently from the switching on/off of the starter motor. At the first stage we neglect the whole starting process. The functional drawing of the new PEM is shown in Figure 4. 
It contains the following parts: DC motor with rotating potentiometer (servo motor) (1), rotational to translational transducer (2) and drive pinion (3). The rotation to translation transducer can be realized with a cam follower system.

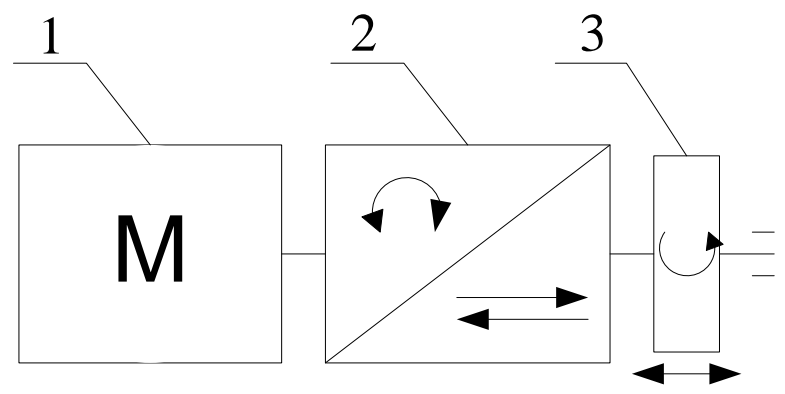

Fig 4.: Functional drawing of the new PEM

A cam is a versatile, specially shaped part of a machine that is always in contact with a member called the follower. The most significant advancement of cam systems has resulted from the application of the digital computer. New techniques and information are available for cam synthesis, analysis and dynamics. Several authors have proposed applications for improving the kinematic and dynamic behavior of camfollower mechanisms [9], [11], [20].

The cam mechanism design includes two stages. The selection of transfer functions which fulfill prescribed kinematical specifications, and the optimization of the mechanism geometry, regarding constructive restrictions [9]. The cam shape may be determined the transfer function of the mechanism. Dependent upon the values of the follower velocity and acceleration at the start and at the end of each transient region. The displacement diagram is a rectangular layout of the follower motion in one cycle of cam operation. The rise of the follower (output motion) is shown as the ordinate. The abscissa is divided into equal cam angles or equal time divisions. The displacement diagram is generally sketched as the first step in the development of the cam profile [1], [9], [11], [22]. In all cams, the displacement of the follower is given by the mathematical relationship. For a cam follower system, the follower displacement, $s(t)$, is a function of cam rotation angle $\square(t)$. Mathematically it can be expressed as:

$$
s(t)=f(\Theta(t)) \square
$$
1 .

The follower acceleration can be obtained from Equation

$$
a(t)=f^{\prime \prime}(\Theta) \dot{\Theta}^{2}(t)+f^{\prime}(\Theta) \ddot{\Theta}(t) \square
$$

These equations present the kinematic relationship between the cam input angular velocity $\square(t)$ and the follower output motion $s(t), v(t), a(t)$ and jerk $j(t)$. Figure 5. shows different basic acceleration curves. The selection of the suitable acceleration is based on the jerk function. That curve suits to the less jerk-like behaviour (delicate motion), which provide the smallest maximum value for the jerk. This is one of the explanations why we cannot choose the suitable acceleration and velocity parameters. Usually the selection is done on the price of compromises due to operation's parameters since the most adverse jerk value construction may suit to the given task.

In our cam design the acceleration functions selected as sinusoidal, and 3-4-5 degree polynomial functions, since these functions meet the most machine design requirements. In addition to these we may obtain better performance for wear, stress, shock, noise, cam surface fatigue and the lowest amplitudes for vibrations, etc.

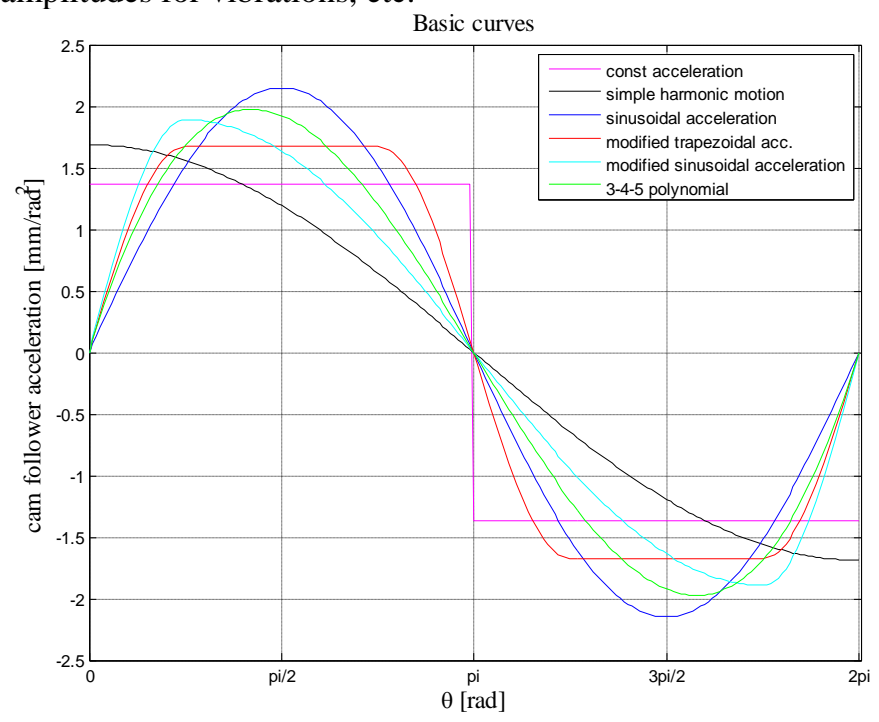

Fig. 5.: Basic acceleration curves

The selected mechanism, which fulfils the requirements, is a cylindrical roller follower mechanism. There are 4 possible concept variants shown in Table 2 .

\section{TABLE II. Concept variants}

\begin{tabular}{|l|l|l|l|l|}
\hline Motion program & Function & $(\square)$ & Cam angle rotation & Form of the cam shape \\
\hline DRD & Polynomial & $180^{\circ}$ & $+180^{\circ}-180^{\circ}$ & opened \\
\hline DRD & Trigonometric & $180^{\circ}$ & $+180^{\circ}-180^{\circ}$ & opened \\
\hline DRRD & Polynomial & $360^{\circ}$ & $+180^{\circ}+180^{\circ}$ & closed \\
\hline DRRD & Trigonometric & $360^{\circ}$ & $+180^{\circ}+180^{\circ}$ & closed \\
\hline
\end{tabular}

In Table 2. the total rise angle $\square \square$ defines the cam angle $\square$ of the DC motor driving the mechanism.. If the total rise angle $\square$ is 180 degrees then dc motor also rotate 180 degrees and the drive pinion-flywheel gear connection will be engaged. After the adverse rotation with 180 degrees the connection will be disengaged. Only the first variant of the above solutions in Table 3 has been manufactured, since the 
rest variants can be easily developed from it. The displacement function is:

$$
s(t)=h\left[10\left(\frac{\Theta}{\beta}\right)^{5}-15\left(\frac{\Theta}{\beta}\right)^{4}+6\left(\frac{\Theta}{\beta}\right)^{3}\right]
$$

\section{EXPERIMENTAL RESULTS}

In the first phase we adjusted the parameters of the servo motor and the servo controller to produce the required motions. In the second phase the test bench worked at least 300000 cycles continuously without real life load. We tested the axial movement of the pinion, the heat of the motor and the time of 1cycle. The test was successfully, and the mechanism had been not significant abrasion and not sign fatigue.

We built up the electromechanical model of the new PEM. The model is described by a nonlinear system of differential equations. The simulation of the PEM was performed by Matlab. Figure 5. shows the simulation results of the drivepinion displacement versus time. The dash line denote the results of the new PEM. The red line denote the analyzed PEM.

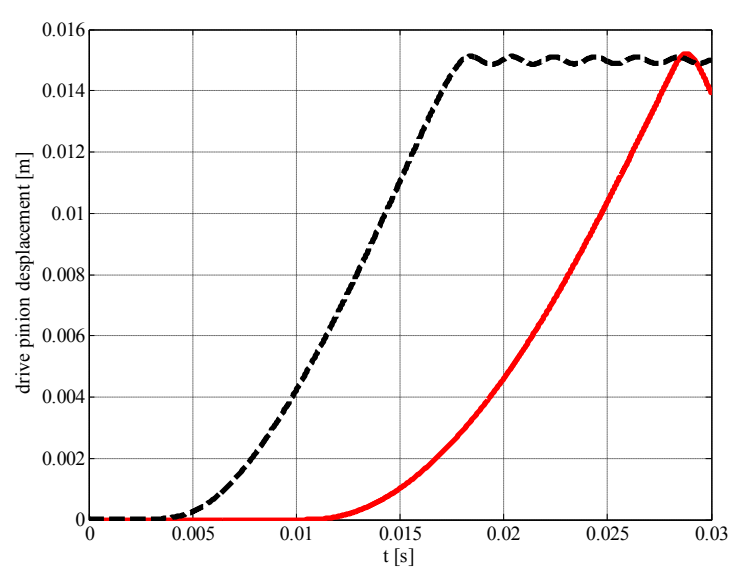

Fig. 6.: Simulation results

\section{CONCLUSION}

The paper presented of a mechatronic design process at the conceptual design stage. The method is based on traditional design method. The paper described a new pinion-enganging mechanism which is fulfill the requiremnts of the modern starting system.

\section{Acknowledgment}

This research was (partially) carried out in the framework of the Center of Excellence of Mechatronics and Logistics at the University of Miskolc.

\section{References}

[1] Chiou, S-J. - Kota, S.: Automated conceptual design of mechanisms, Mechanism and Machine Theory 34 (1999) pp. 467-495.

[2] G. Pahl-W. Beitz: Engineering Design. London, The Design Council, 1984.

[3] ISERMANN, R.: Mechatronic systems-Innovative products with embedded control, Control Engineering Practice 16 (2008) pp. 14-29.

[4] Janschek, K.: Mechatronic Systems Design, Methods, Models, Concepts, Springer, 2012

[5] Meyer, R., Braun H., Rehage R., Weinmann H., Alternators and Starter Motors, Robert Bosch GmbH, 2003.

[6] NAGy, L. - SzABÓ, T. - JAKAB, E.: ElectromeChaniCAL MODElLiNG OF A PINION ENGAGING MECHANISM FOR STARTER MOTORS, POLLACK PERIODICA, AN INTERNATIONAL JOURNAL FOR ENGINEERING AND INFORMATION SCIENCES, VOL. 8, NO. 1, PP. 97-108 (2013) ISSN 17881994, DOI: 10.1556/POLLACK.8.2013.1.9

[7] NAGY, L. - SzABÓ, T.- JAKAB, E.: Electro-dynamical Modelling of a Solenoid Switch of Starter Motors, Procedia Engineering (48) 2012. pp. 445-452. ISSN 1877-7058 Elsevier http://dx.doi.org/10.1016/j.proeng.2012.09.538.

[8] Neugebauer, R. - Denkena, B. - Wegener, K.: Mechatronic Systems for machine tools, Annals of the CIRP Vol. 56/2/2007. pp. 657-686. doi:10.1016/j.cirp.2007.10.007.

[9] Norton, R .L: Cam Design and Manufacturing Handbook, New York, Industrial Press, 2002.

[10] Preumont, A. Mechatronics, Dynamics of Electromechanical and Piezoelectric Systems, Springer 2006.

[11] Rothbart, H. A.: Cam Design Handbook, New York, McGraw-Hill, 2004.

[12] SuH, N. P.: The Principles of Design, Oxford University Press, New York, 1990 .

[13] Tajnaföi, J: Szerszámgéptervezés II. Budapest, Tankönyvkiadó, 1990.

[14] Tomiyama, T. -P. GU, P. - Jin Y.- LutTers, D. - Kind, CH.- KimuRA, F.: Design methodologies: Industrial and educational applications, CIRP Annals - Manufacturing Technology 58 (2009) pp. 543-565.

[15] Vajna, S.: Theories and methods of product development and design, Gépészet 2008 Budapest, 29-30.May 2008. G-2008-P-02 p 23.

[16] VDI 2206: Design methodology for mechatronic systems, Düsseldorf, 2004.

[17] VDI 2221 Richtlinie: Methodik zum Entwickeln und Konstruieren technischer Systeme und Produkte, 1993 (VDI-Verlag: Düsseldorf).

[18] VDI Richtlinie 2222 B1. 1: Methodisches Entwickeln von Lösungsprinzipien. Düsseldorf, 1997.

[19] VDI Richtlinie 2225 Bl. 1 und B1. 2: Technisch-wirtschafliches Konstruieren. Düsseldorf, 1977.

[20] Volmer, J: Bütykös mechanizmusok,Budapest, Műszaki Könyvkiadó, 1980.

[21] Y, Zeng - S, Yao: Understanding design activites through computer simulation, Advanced Engineering Informatics (23) 2009. pp. 294-308. 